\title{
Case Report \\ Intraoral Superficial Angiomyxoma of the Upper Alveolus: Report of a Unique Case
}

\author{
Ravindra S. V., ${ }^{1}$ M. Srinivasa Raju, ${ }^{1}$ Sunitha J. D., ${ }^{2}$ Neeraj Taneja, ${ }^{1}$ Sunira Chandra, ${ }^{1}$ \\ Shveta Mahajan, ${ }^{1}$ and Eesha Panwar ${ }^{2}$ \\ ${ }^{1}$ Department of Oral Medicine and Radiology, Teerthanker Mahaveer Institute of Dental Sciences and Research Centre, \\ Teerthanker Mahaveer University, Bagarpur, Delhi Road, Moradabad 244001, India \\ ${ }^{2}$ Department of Oral Pathology and Microbiology, Teerthanker Mahaveer Institute of Dental Sciences and Research Centre, \\ Teerthanker Mahaveer University, Bagarpur, Delhi Road, Moradabad 244001, India
}

Correspondence should be addressed to Ravindra S. V., drravindrasetru@gmail.com

Received 28 March 2012; Accepted 3 May 2012

Academic Editor: Ting Fan Leung

Copyright ( 2012 Ravindra S. V. et al. This is an open access article distributed under the Creative Commons Attribution License, which permits unrestricted use, distribution, and reproduction in any medium, provided the original work is properly cited.

Angiomyxomas are relatively a group of uncommon myxoid mesenchymal tumors characterized by frequent local recurrences and show lack of malignant potential. Basically three types of angiomyxomas are recognized superficial, aggressive, and angiomyofibroblastoma. Though the angiomyxomas are rarely reported in the head and neck region, the paper shows reported cases intraorally in the buccal mucosa and floor of the mouth. Here, the authors report a rare case of angiomyxoma presenting as a growth in the upper posterior alveolar mucosa.

\section{Introduction}

Angiomyxomas are a group of relatively uncommon myxoid mesenchymal tumors characterized by frequent local recurrences and lack of metastatic potential. Three types of angiomyxomas are recognized: aggressive, superficial and angiomyofibroblastoma [1]. Superficial angiomyxoma, also known as cutaneous myxoma [2], was first described by Allen et al. in 1988 and in greater detail in 2000 [3]. Although there have been many reported cases in the head and neck, including sites such as the chin, lip, cheek, nose, ear, forehead, face, and neck; truly intraoral cases are extremely rare [2] with 4 previously reported cases till date occurring in the buccal mucosa and floor of the mouth [2-5]. To the best of our knowledge, we report the first case of an intraoral superficial angiomyxoma, occurring in the upper alveolar mucosa.

\section{Case Report}

A 30-year-old male patient presented with a slow-growing, soft mass in the right upper posterior alveolar region, present since 2 years and which was associated with mild pain upon eating (Figure 1). Patient had noticed a mobile tooth in the same region about a year and a half back and had got it extracted. The swelling had continued to grow slowly after the extraction. His medical history was noncontributory. Examination showed that the lesion was diffuse, reddish, slightly ulcerated, and measuring about $3 \times$ $3 \mathrm{~cm}$ in size. It was rubbery to firm in consistency and mildly tender, with slight bleeding on palpation. Radiographs were taken but no changes were observed. Incisional biopsy was performed. Microscopic examination revealed epithelium overlying loose myxoid stroma accompanied by a prominent vasculature (Figure 2). Myxoid stroma showed a scattered spindle to stellate-shaped cells which had distinct borders and oval nuclei. There was no cellular or nuclear atypia or hyperchromasia and mitotic activity and necrosis were not present. Small, thin-walled curvilinear blood vessels were prominent throughout the stroma. A mild inflammatory infiltrate was present predominantly neutrophils (Figure 3 ). An immunohistochemical staining was performed using vimentin and CD34 antigens. Most of the stromal tumor cells were immunopositive for vimentin (Figure 4) and the 


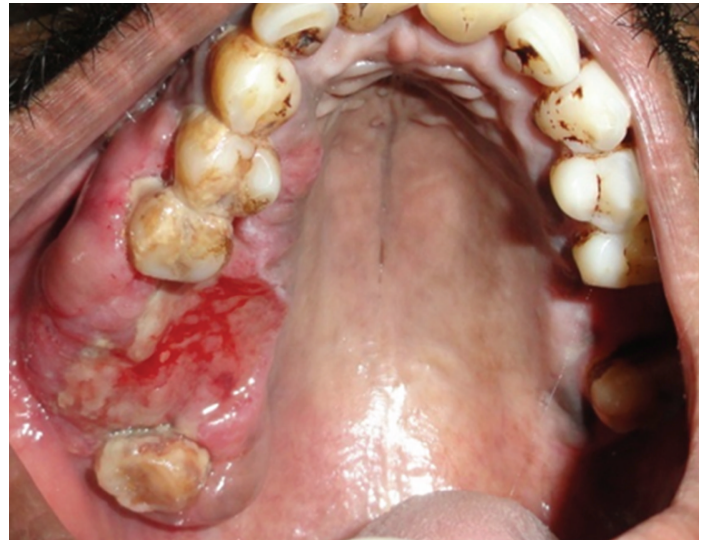

Figure 1: Diffuse, reddish, and slightly ulcerated lesion in the right alveolar region.

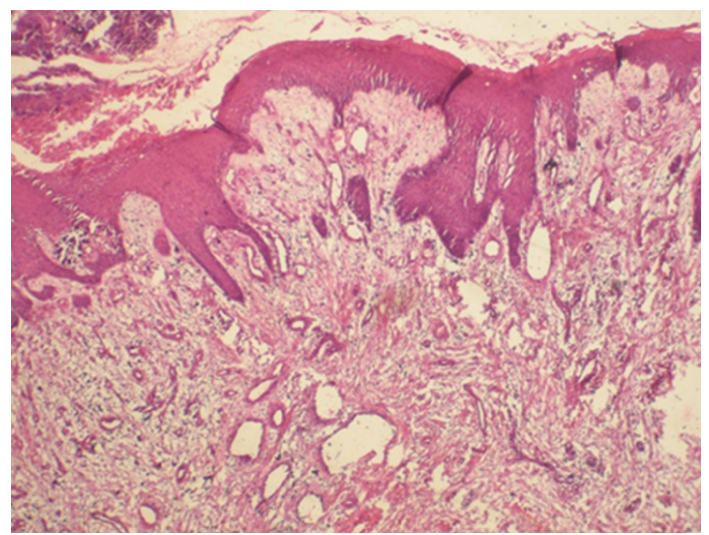

Figure 2: Photomicrograph showing stratified squamous epithelium overlying myxoid connective stroma with prominent vasculature (hematoxylin and eosin stain, $4 \mathrm{x}$ ).

endothelial cells of the blood vessels displayed immunoreactivity for CD34 (Figure 5). This confirmed the diagnosis of superficial angiomyxomas. Treatment was not done due to patient unwillingness.

\section{Discussion}

Superficial angiomyxomas are rare distinctive, benign, cutaneous soft tissue lesions with a predilection for the trunk, head, and neck; other sites being lower extremities and genital area [2]. Cutaneous superficial angiomyxomas typically present as polypoid or papulonodular lesions that may be confused with a cyst, skin tag, or neurofibroma. There is a slight male predilection and most cases present in middle age although rare congenital examples have been reported as well [3]. However, these tumors can also occur within the oral cavity [2]. A brief outline of the previously reported oral superficial angiomyxomas is summarized in Table 1. There are still too few documented intraoral cases to draw meaningful clinical comparisons. The distinctive histological features of superficial angiomyxoma include a multilobular

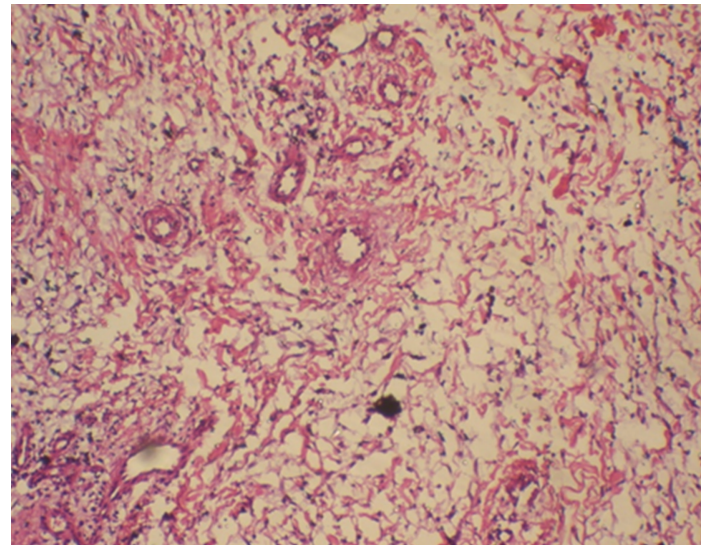

Figure 3: Photomicrograph showing loose collagenous myxomatous stroma permeated by spindle shaped cells and nonarborizing blood vessels (hematoxylin and eosin stain, 10x).

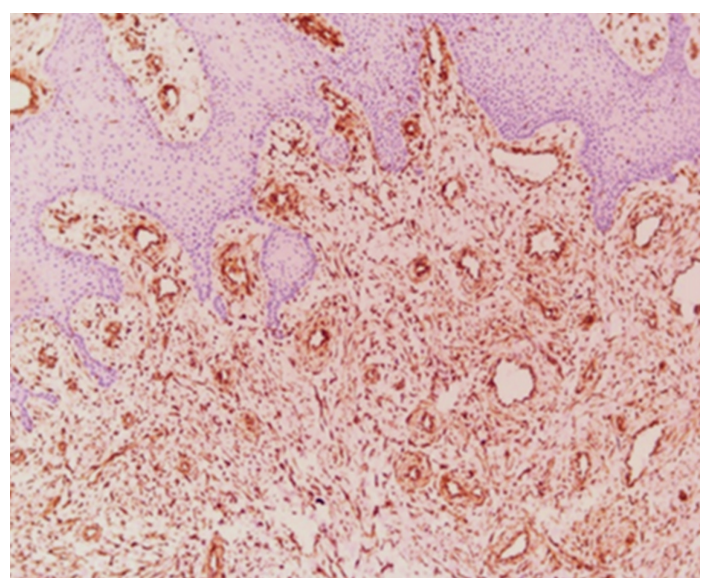

FIgURE 4: Many tumor cells stained strongly for vimentin (10x).

growth pattern composed of spindle-shaped to stellate cells in a copious myxoid stroma. Small, thin-walled vessels are prominent and there is presence of stromal inflammatory cells, especially neutrophils which is an important diagnostic clue $[1,2]$.

The main histologic differential diagnosis for intraoral tumors includes aggressive angiomyxoma, soft tissue myxoma, angiomyolipoma, myxoid nerve sheath tumor (neurothekeoma), myxoid neurofibroma, oral focal mucinosis, and myxofibroma or odontogenic myxoma.

Aggressive angiomyxoma can be distinguished from its superficial and angiomyofibroblastoma counterparts by the proliferation of spindle- or satellite-shaped cells that are widely separated by loose myxoid stroma in which there are prominent and large vascular components $[1,2]$.

Angiomyolipoma is composed of a mixture of thickwalled blood vessels, smooth muscle, and adipose tissue found mostly in the kidney [4]. Neither smooth muscle nor adipose tissue were seen in the tumor tissue of the current case. Nerve sheath myxoma has smaller individual nodules, is less vascular with cells arranged concentrically like a Pacinian 
TABLE 1: Reported cases of intraoral superficial angiomyxoma.

\begin{tabular}{|c|c|c|c|c|c|c|c|}
\hline Reference & Site & Age & Gender & Race & Size $(\mathrm{mm})$ & Presentation & Clinical impression \\
\hline Chen et al. [4] & Right buccal mucosa & $19 \mathrm{yrs}$ & Male & Chinese & $50 \times 35 \times 30$ & $\begin{array}{l}\text { Slow growing painless } \\
\text { lump present for } 2 \text { years }\end{array}$ & Soft tissue tumor \\
\hline Gardner [3] & Floor of the mouth & $69 \mathrm{yrs}$ & Female & European & $10 \times 12 \times 12$ & $\begin{array}{l}\text { Slow growing painless } \\
\text { lump present for } 3 \text { years }\end{array}$ & Lipoma \\
\hline Meer and Beavon [2] & Right buccal mucosa & $37 \mathrm{yrs}$ & Female & African & $45 \times 32 \times 20$ & $\begin{array}{l}\text { Slow growing painless } \\
\text { lump present for } 2 \text { years }\end{array}$ & Lipoma \\
\hline Mokhtar et al. [5] & Floor of the mouth & 6 months & Male & Malaysian & $50 \times 36 \times 26$ & $\begin{array}{l}\text { Slow growing swelling } \\
\text { noticed when patient } \\
\text { was 5-month-old }\end{array}$ & $\begin{array}{c}\text { Soft tissue } \\
\text { tumor/cystic } \\
\text { swelling } \\
\end{array}$ \\
\hline Present case & $\begin{array}{l}\text { Upper posterior } \\
\text { alveolar region }\end{array}$ & $30 \mathrm{yrs}$ & Male & Indian & $30 \times 30$ & $\begin{array}{l}\text { Slow growing painless } \\
\text { swelling present for } 1 \\
\text { and a half years }\end{array}$ & Soft tissue tumor \\
\hline
\end{tabular}

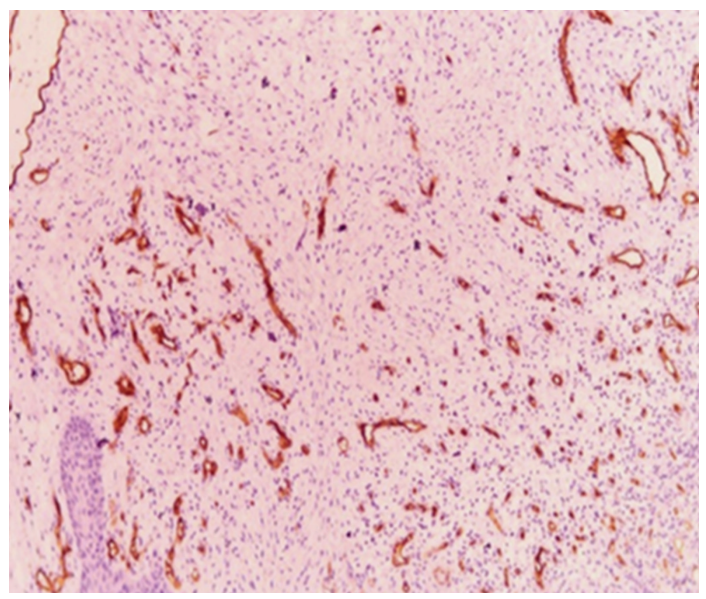

FIGURE 5: The endothelial cells of the blood vessels stained strongly for CD34 (10x).

corpuscle, and contains occasional eosinophilic histiocytic cells. The cells of myxoid neurofibroma are typically slender with wavy nuclei and intralesional nerve bundles. Oral focal mucinosis is typically acellular with very few blood vessels, lack of a lobular architectural pattern, and no stromal inflammation [2]. Myxofibromas or odontogenic myxomas are central lesions that are diffuse and nonlobulated, with no stromal inflammation, and may contain odontogenic epithelial rests. Superficial angiomyxomas are generally immunoreactive with vimentin and CD34, which was consistent with the present case. Treatment is by localized surgical excision, with careful followup owing to its high rate of local recurrence between $20 \%$ and $40 \%$ [2-4]. Superficial angiomyxomas have an overall good prognosis as this lesion stays superficial, without affecting deeper structures $[2,4]$.

\section{Conclusion}

Superficial angiomyxoma is clearly a very rare neoplasm of the oral cavity and should be included in the differential diagnosis of myxoid intraoral soft tissue neoplasms.

\section{References}

[1] Y. Yamashita, O. Tokunaga, and M. Goto, "Aggressive angiomyxoma of the oral floor: report of a case," Journal of Oral and Maxillofacial Surgery, vol. 62, no. 11, pp. 1429-1431, 2004.

[2] S. Meer and I. Beavon, "Intraoral superficial angiomyxoma," Oral Surgery, Oral Medicine, Oral Pathology, Oral Radiology and Endodontology, vol. 106, no. 5, pp. e20-e23, 2008.

[3] A. W. Gardner, "Superficial angiomyxoma of the floor of the mouth-A case report," British Journal of Oral and Maxillofacial Surgery, vol. 45, no. 5, pp. 418-419, 2007.

[4] Y. K. Chen, L. M. Lin, C. C. Lin, and Y. H. Yan, "Myxoid tumor of the oral cavity with features of superficial angiomyxoma: report of a case," Journal of Oral and Maxillofacial Surgery, vol. 56, no. 3, pp. 379-382, 1998.

[5] S. M. Mokhtar, R. Z. R. Shahardin, M. Z. Abidin, and R. A. Rahman, "Superficial angiomyxoma of the floor of the mouth in an infant," Asian Journal of Oral and Maxillofacial Surgery, vol. 20, no. 1, pp. 26-28, 2008. 


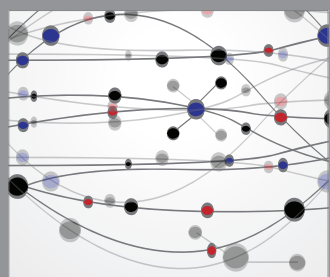

The Scientific World Journal
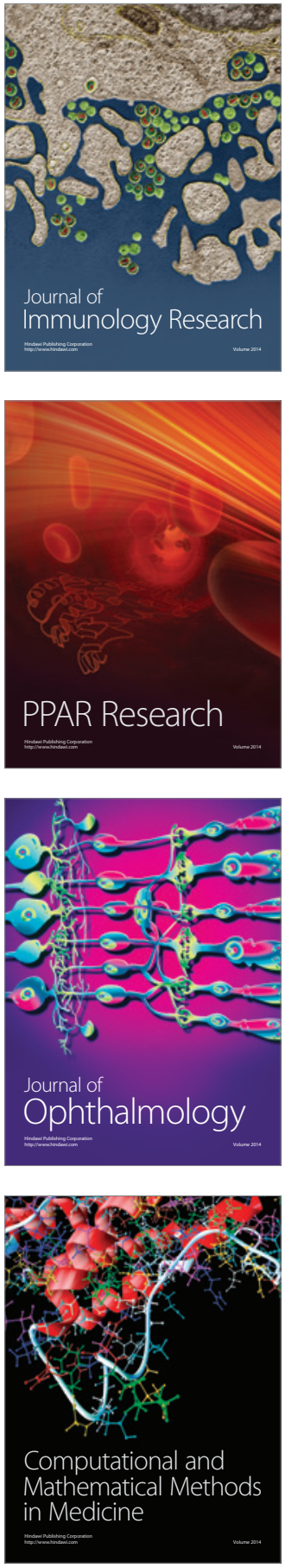

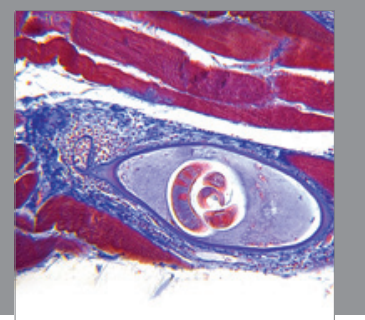

Gastroenterology

Research and Practice
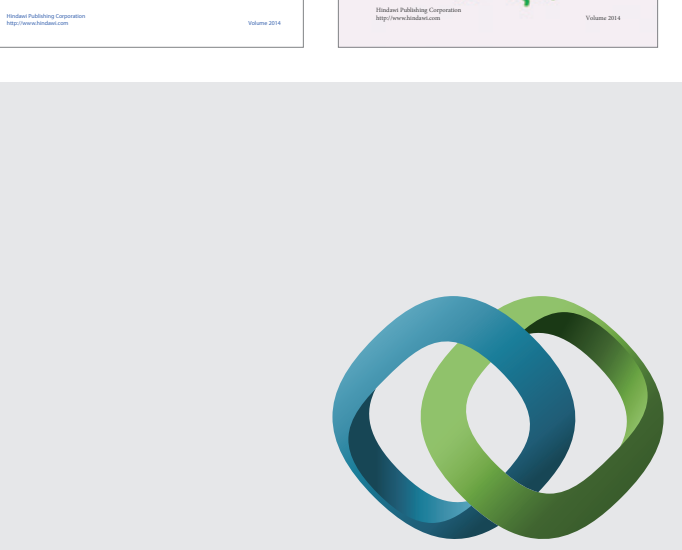

\section{Hindawi}

Submit your manuscripts at

http://www.hindawi.com
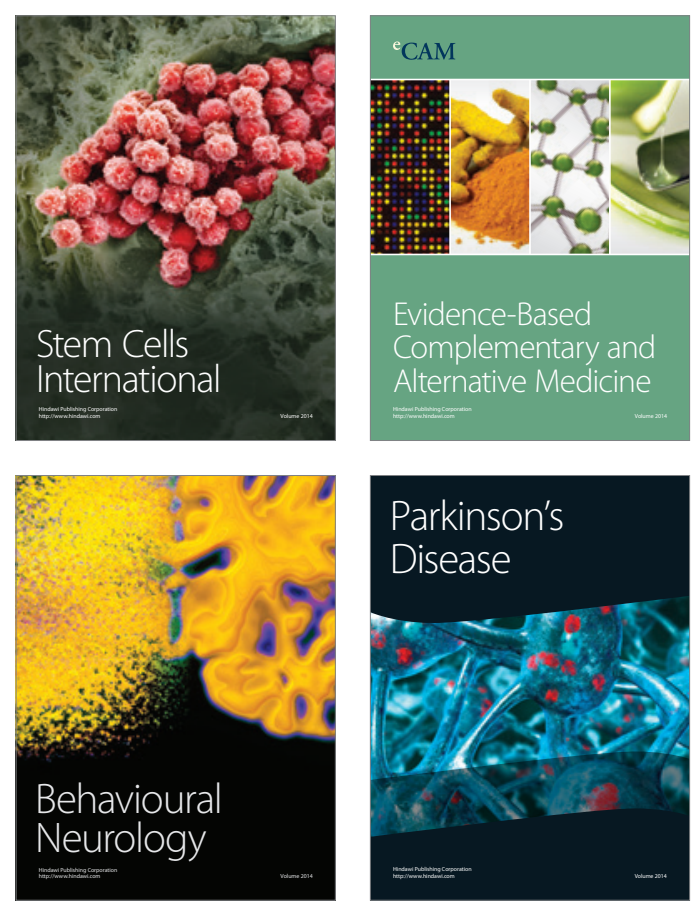

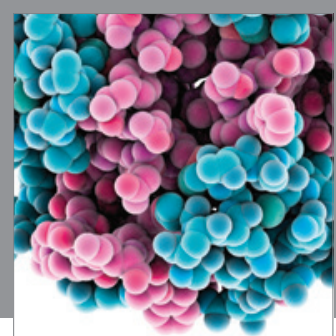

Journal of
Diabetes Research

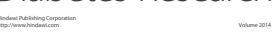

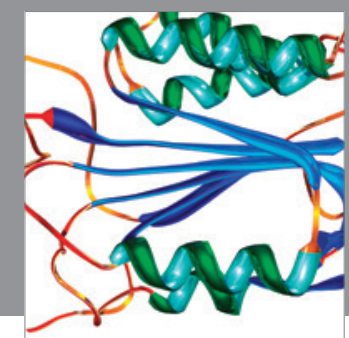

Disease Markers
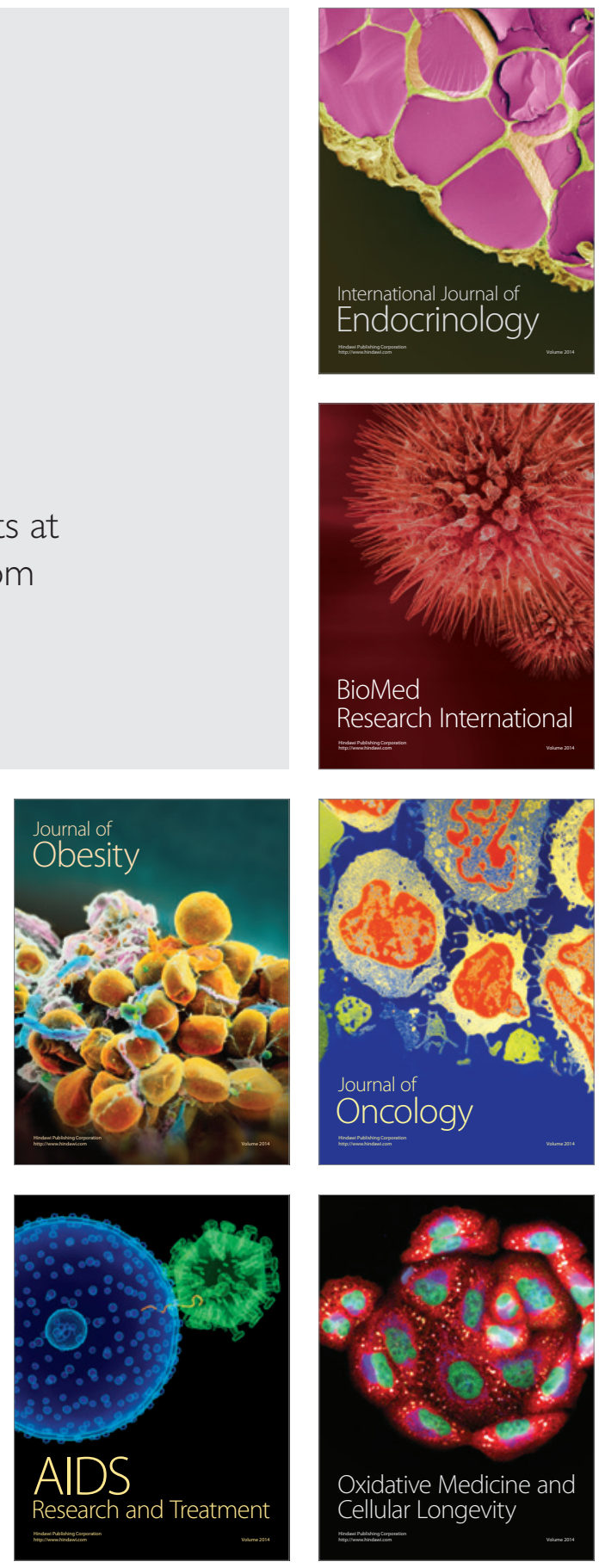